\title{
Cortical correlates of response time slowing in older adults: ERP and ERD/ERS analyses during passive ankle movement
}

\author{
Diana R. Toledo ${ }^{\mathrm{a}, *}$, Gilberto M. Manzano ${ }^{\mathrm{b}}$, José A. Barela ${ }^{\mathrm{c}, \mathrm{d}}$, André F. Kohn ${ }^{\mathrm{a}}$ \\ a Neuroscience Program and Biomedical Engineering Laboratory, University of São Paulo, EP-USP, PTC, São Paulo, Brazil \\ ${ }^{\mathrm{b}}$ Division of Neurology, Federal University of São Paulo, São Paulo, Brazil \\ ${ }^{\mathrm{c}}$ Institute of Physical Activity and Sport Sciences and Graduate Program in Human Movement Sciences, Cruzeiro do Sul University, São Paulo, Brazil \\ ${ }^{\mathrm{d}}$ Institute of Bioscience, São Paulo State University, Rio Claro, Brazil
}

\section{A R T I C L E I N F O}

Article history:

Accepted 2 May 2015

Available online 9 May 2015

\section{Keywords:}

Aging

Proprioception

Passive movement

Event-related potential

Beta ERD/ERS

\section{H I G H L I G H T S}

- During passive ankle movement, older adults showed lower amplitude and longer latency of the N1 component than young adults, which correlated with their delayed response time.

- Larger beta event-related desynchronization (ERD) in a response time task in older adults may be an indication of a higher cognitive effort to process weaker proprioceptive inputs (lower N1).

- Attenuated beta event-related synchronization (ERS) in older adults may be related to changes in intracortical inhibitory activity.

\begin{abstract}
A B S T R A C T
Objectives: The response time (RT) to kinesthetic perception has been used as a proprioceptive measurement, for example, in older individuals. However, the RT cannot provide information on impairments at specific stages of the respective sensorimotor processing. In the present study, electroencephalographic (EEG) signals were recorded during passive ankle movement with and without an associated perceptual task of movement detection. The main purpose was to analyze differences between young and older adults both in terms of RT and cortical responses. Putative differences in the latter were expected to point to changes in the processing associated with neural pathways or cortical regions in the older subjects. Methods: The EEG activity of nineteen older (OA, 65-76 years) and 19 young adults (YA, 21-32 years) was recorded during passive ankle movement, without motor voluntary response (NVR, sensory condition), and during a condition with voluntary motor response (VR, with measurement of the RT). Event-related potentials (ERP) and beta event-related desynchronization/synchronization (ERD/ERS) were recorded and analyzed in both experimental conditions.

Results: The RT in OA was larger than in YA $(P<0.0001)$. EEG analyses showed that the N1 amplitude was larger in the VR than in the NVR condition $(P=0.006)$, whereas no difference for latency was obtained between conditions $(P=0.376)$. Comparisons between the groups revealed attenuated $(P=0.019)$ and delayed $(P=0.001) \mathrm{N} 1$ in the OA group, irrespective of the condition (no interaction group vs condition). Only OA showed correlations between RT and N1, with significant correlation for both amplitude $(r=-0.603, \quad P=0.006)$ and latency $(r=0.703, \quad P=0.001)$. The ERD/ERS analyses revealed a task-dependent group effect: in NVR, significant differences were obtained only for the ERS amplitude, which was attenuated in OA $(P=0.003)$. In VR, larger $(P=0.004)$ and delayed $(P=0.003)$ ERD and attenuated $(P=0.029)$ and delayed $(P=0.017)$ ERS peaks were observed in the older group.

Conclusions: The results suggest that a larger response time to proprioceptive stimuli in older adults is associated with a weaker and delayed proprioceptive afferent inflow to the cortex. In this scenario, older adults would need a higher cognitive effort (larger ERD) to process the sensory inputs when attempting to properly perform a sensorimotor task.
\end{abstract}

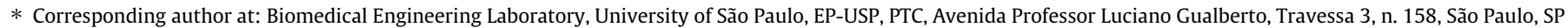
05508-900, Brazil. Tel.: +55 1130919792.

E-mail address: dianatoledo12@hotmail.com (D.R. Toledo).
} 
Significance: ERP and ERD/ERS measurements during kinesthetic assessment provide new insights on identification of the origin of sensorimotor slowing in older adults.

๔ 2015 International Federation of Clinical Neurophysiology. Published by Elsevier Ireland Ltd. All rights reserved.

\section{Introduction}

Several studies have provided evidence that proprioceptive sense is reduced as a consequence of aging (for a review, see (Goble et al., 2009)) and that this change is associated with decreased performance in sensorimotor tasks such as posture and gait. For instance, reduced postural stability in older adults has been related to proprioceptive impairment in the lower limbs (Fitzpatrick and McCloskey, 1994; Lord and Ward, 1994; McChesney and Woollacott, 2000; Toledo and Barela, 2014).

The most common methods for examining the proprioceptive sense involve behavioral measurements such as replication of a predetermined target joint position either with the same (ipsilateral) or with the contralateral limb (Skinner et al., 1984; Lephart et al., 1997; Deshpande et al., 2003; Pickard et al., 2003; Amin and Herrington, 2014) and response time to motion sense (Thelen et al., 1998; Tomberg, 1999; Deshpande et al., 2003; Salles et al., 2011; Toledo and Barela, 2014). As measurements of performance, both are limited in quantifying possible proprioceptive impairment per se (e.g., proprioceptive loss due to aging or neuropathy) since both measurements can be also influenced by cognitive and motor factors. A promising approach for investigating the neurophysiological aspects of proprioceptive function is the association of passive joint movement to different techniques such as microneurography (Burke et al., 1988; Ribot-Ciscar et al., 2013), electroencephalography (EEG) (Cassim et al., 2001; Lewis and Byblow, 2002; Seiss et al., 2002; Keinrath et al., 2006), and transcranial magnetic stimulation (TMS) (Lewis et al., 2001; Lewis and Byblow, 2002). The combination of these techniques can be very useful in the study of how different stages of information transmission and processing are involved in a cognitive sensorimotor task. However, electrophysiological analyses during proprioceptive tasks are still little explored in older adults and, therefore, the specific impairments that lead to their lower performance in proprioceptive assessment (e.g., increased response time) remains to be determined.

Age-related impairments at specific stages of neural signal processing and generation during sensorimotor tasks were previously reported for other stimulus modalities (Yordanova et al., 2004). Analyses based on event-related potentials (ERPs) showed that increased response time to visual and auditory stimuli in older adults was correlated with late cortical processing related to response generation (i.e., motor-related potential) (Yordanova et al., 2004), but was not related to early sensory processing stages. Whether the origin of response time slowing in older adults is independent of stimulus modality is still unknown, thus, the results obtained for visual and auditory stimuli cannot be extrapolated to somatosensory stimuli.

Beyond ERP analyses, recent studies provided important clues concerning the stimulus processing during kinesthetic assessment by showing that specific cortical rhythms (e.g., beta band from 14 to $37 \mathrm{~Hz}$ ) can be altered during passive joint movement (Cassim et al., 2001; Muller-Putz et al., 2007; Salles et al., 2011). Increased cortical activity at a specific frequency band is called event-related synchronization (ERS) (Pfurtscheller et al., 2006). Based on the evidence of reduced motor-evoked potential (MEP, assessed by TMS) at the same time of ERS occurrence during active movement, the cortical synchronization is interpreted as a cortical state of reduced excitability (Chen et al., 1998). The functional meaning of ERS during passive movements is not known precisely, but there is evidence that it also involves somatosensory processing, given that the ERS induced by passive index finger movement disappears after deafferentation by ischaemic nerve block (Cassim et al., 2001). On the other hand, reduced cortical activity at specific frequency bands is called event-related desynchronization (ERD) (Niedermeyer and Lopes da Silva, 1999) and has been associated with increased cortical excitability. ERD/ERS analyses can provide complementary data to the ERP findings and may clarify important aspects regarding the aging effects on the dynamics of brain oscillations during a sensorimotor task, such as passive ankle movement.

The goal of the present study was to investigate the cortical changes during the assessment of the proprioceptive system during passive ankle movement in young and older adults. For this purpose, ERP and ERD/ERS analyses were compared between conditions in which the subject was instructed either only to attend or to attend and respond (press a button) to the perception of passive ankle movement. The first condition provides specific information related to the sensory processes involved in the sensorimotor response time task. Additionally, the responses were compared between young and older adults in an effort to shed some light on the effects of aging on cortical processing of proprioceptive inputs associated with the ankle.

\section{Methods}

\subsection{Participants}

Nineteen older (OA, $70.3 \pm 4.1$ years; $65-76)$ and 19 young (YA, $28.5 \pm 2.9$ years; $21-32$ ) right-footed adults (10 females in each group) participated in this study. They were recruited from graduate programs, local communities, and a cultural center for retirees. The older participants were chosen among those who had not been enrolled in any regular physical activity program (for at least three years), had not suffered any falls in the last two years, had no vestibular impairment, pain, visual, osteomuscular and/or neurological disorders, and had not made use of benzodiazepine or antidepressant drugs. The average height and weight of the young participants were $1.67( \pm 0.08) \mathrm{m}$ and $68.16( \pm 11.97) \mathrm{kg}$, respectively. For the elderly group, the average height and weight of the participants were $1.62( \pm 0.10) \mathrm{m}$ and $65.24( \pm 11.71) \mathrm{kg}$, respectively. Anthropometric measurements were not statistically different between groups.

\subsection{Procedures}

This study was conducted in accordance with the Declaration of Helsinki and its procedures were approved by the Institutional Ethics Committee. In addition, all procedures were carried out with adequate understanding and written consent from each participant.

Participants were seated comfortably on a customized chair with armrest and headrest. Their right foot rested on a pedal (Fig. 1) and was not visible to the subject because the hip and knee angles were at $90^{\circ}$ and the subject was required to stare straight ahead. The right ankle was passively dorsiflexed at $22 \%$, from a starting ankle angle set at $90^{\circ}$ and then returned to the basal angle with similar speed. The low noise produced by the motor was 


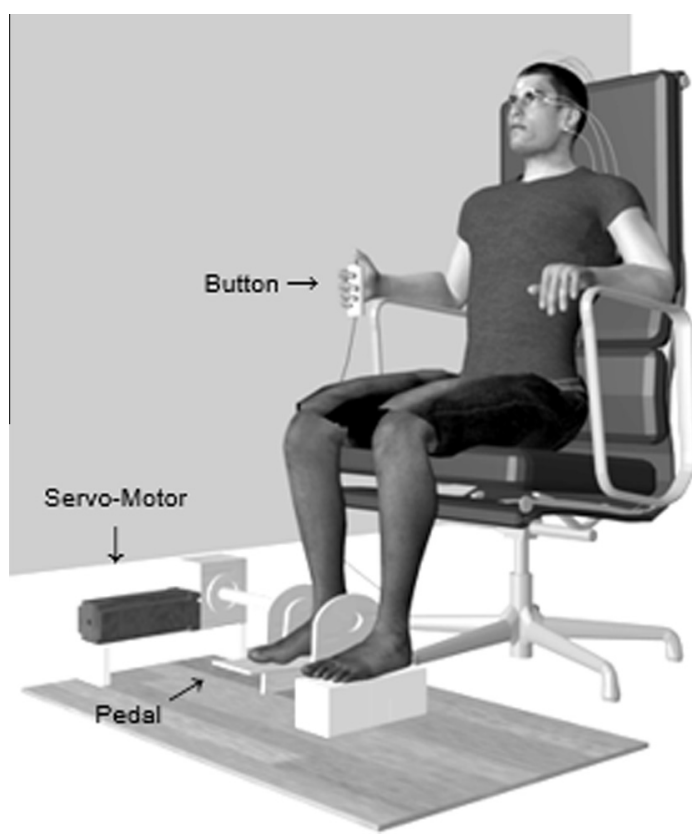

Fig. 1. Experimental setup. For NVR the subject did not have to press the button while for the VR he had to press the button as soon as he perceived movement of the pedal.

masked by the $10 \mathrm{~dB}$ noise generated by the air conditioner of the experiment room. Therefore, there were no visual or auditory cues and hence the movement perception was based solely on the somatosensory system. The pedal's movement was produced by a system consisting of a servo-motor (AC Brushless Servo-Motor, Model SWA-40-1.630), a reducer (Dynabox Medium - France) and a servo electronic (Weg - Brazil). The analog signal to command the servo-controller was generated via Labview software (National Instruments, USA).

Total movement lasted about $1 \mathrm{~s}(0.5 \mathrm{~s}$ in each direction) (Muller-Putz et al., 2007) and was registered using IREDs of an Optotrak system (Certus, NDI, Inc.).

Two experimental conditions were presented in the following order: (1) without the subject's voluntary response (no voluntary response, NVR) and (2) with the subject's voluntary response (VR). In the NVR condition, no instructions were given to the subjects with regard to any particular cognitive task. Subjects were only instructed to look straight ahead and to avoid blinking during ankle movements, without any knowledge about the second condition. Hence, this condition was considered as a sensory task. In the VR condition, subjects were instructed to press a button with their right thumb as fast as possible whenever the ankle dorsiflexion movement onset was detected, so the RT was obtained. This condition was considered as a sensorimotor task. Passive movement was initiated at random times, starting between 3 and $9 \mathrm{~s}$ after movement offset. Assuming that the movement lasted $1 \mathrm{~s}$, the interstimulus interval (ISI, considering the movement onset) ranged from 4 to $10 \mathrm{~s}$ (mean ISI $=7 \mathrm{~s}$ ). For each condition, approximately 75 movements were performed in three 3 -min trials, with 1 -min rest between each trial.

\subsection{EEG recordings}

Five $\mathrm{Ag} / \mathrm{AgCl}$ surface electrodes were mounted around electrode position $\mathrm{Cz}$ ( $\mathrm{FCz}, \mathrm{Cz}, \mathrm{CPz}, \mathrm{C} 1$ and $\mathrm{C} 2$ ), defined by the international 10-20 and 10-10 systems (Jasper, 1958; Reily, 1999), with the reference at linked earlobes and the ground electrode at forehead. Two additional electrodes were used to record the horizontal and vertical eye movements in the electrooculogram (EOG), one supraorbital and the other one $2 \mathrm{~cm}$ external to the outer cantus of the right eye. The impedance of the EEG electrodes was kept below $5 \mathrm{k} \Omega$ during the recording.

EEG signals were amplified and band-pass filtered (0.05$100 \mathrm{~Hz}$ ) using a MEB 4200 system (Nihon-Koden, Japan), acquired at a sampling frequency of $1 \mathrm{kHz}$ and monitored continuously through the Optotrak data acquisition unit (ODAU).

\subsection{Data processing}

All data and signal processing was performed through custom-written routines in Matlab (Math Work Inc., USA). The EEG recording epoch was referenced to ankle movement onset, with a total length of $6 \mathrm{~s}$ ( $2 \mathrm{~s}$ preceding movement onset and $4 \mathrm{~s}$ after movement onset). Orthogonal source derivation was calculated to obtain reference-free data (Hjorth, 1975). Contaminated trials were rejected when EEG or EOG records exceeded $\pm 100 \mu \mathrm{V}$. Individual averages (from a number of sweeps between 40 and $60)$ for each condition were obtained.

N1 component: this component was defined as the most negative deflection within $0-300 \mathrm{~ms}$ after movement onset. Peak amplitude and latency were identified for each individual average. Peak amplitude was measured with respect to pre-movement baseline activity (reference interval: between 1.5 and $0.5 \mathrm{~s}$ before movement onset). The first positive deflection (P1) was not distinguishable in most subjects, hence, this component was not analyzed. Other positive and negative deflections that followed the $\mathrm{N} 1$ component were also not analyzed, since they could reflect the central processing related not only to dorsiflexion movement, but also to the movement reversion (plantarflexion).

Beta ERD/ERS: the EEG data were band-pass filtered $(14-37 \mathrm{~Hz})$ with a digital Butterworth filter (13th order, zero phase shift). The mean waveform averaged over all trials was subtracted from each time series (evoked potential subtraction). Afterwards, the data were squared and the mean waveform was computed (Graimann et al., 2002). The ERD/ERS was then expressed as a proportional power decrease (ERD) or power increase (ERS) in relation to the reference interval. To improve the analysis of the ERD and ERS signals, only significant changes from each subject were considered for analyses. The detection of intervals with significant ERD or ERS was based on a confidence interval $(\mathrm{CI})$ estimated separately for ERD and ERS, along time from $\mathrm{N}$ epochs obtained from each subject. The rationality for such approach is similar to that presented by Graimann et al. (2002), except that here an asymptotic normal approximation was adopted. It is well known that a random variable $\frac{N S^{2}}{\sigma^{2}}$ is distributed as a $\chi^{2}(N-1)$, where

$S^{2}=\frac{1}{N} \sum_{i=1}^{N}\left(X_{i}-\bar{X}\right)^{2}$

is the sample variance of normally distributed samples $X_{i}$. The filtered EEG samples may be roughly approximated by a normal distribution. For large $N$ the chi-squared distribution with $N-1$ degrees of freedom may be approximated by a normal distribution with mean $N-1$ and variance $2(N-1)$.

From the considerations above, the basic approach was to estimate the variance of the samples in a reference pre-stimulus interval, RIV, and at every time sample $j$ of the post-stimulus signal estimate the $95 \% \mathrm{CI}$ as

$\left[\frac{\sum_{i=1}^{N} y_{i j}}{q_{1}}-R I V, \frac{\sum_{i=1}^{N} y_{i j}}{q_{-1}}-R I V\right]$

where, $y_{i j}$ is the square of the sample $j$ of signal epoch $i$ with the mean evoked potential already subtracted from it; 
$q_{1}=\sqrt{2(N-1)} \cdot 1.96+(N-1) \quad$ and $\quad q_{-1}=-\sqrt{2(N-1)} \cdot 1.96+$ $(N-1)$. If the CI was above the zero line (at least $95 \%$ of the time from 1.2 to $2.5 \mathrm{~s}$ ), an ERS was accepted. On the other hand, if the $\mathrm{CI}$ was below the zero line (at least $95 \%$ of the time from 0 to $1 \mathrm{~s}$ ), an ERD was accepted.

\subsection{Statistical analyses}

As normality and homogeneity assumptions were accepted by appropriate tests, analysis of variance (ANOVA) and multivariate analyses of variance (MANOVAs) were conducted. For the behavioral data, a one-way ANOVA was conducted for comparison between the age groups and the dependent variable was the RT values. For the N1 component, a $2 \times 2$ MANOVA was conducted, with age group and condition as the factors, the latter being treated as a repeated measure, and peak amplitude and peak latency as dependent variables.

In order to investigate the relationship between behavioral and electrophysiological variables, Pearson's correlation coefficient between RT and N1 peak amplitude and between RT and N1 peak latency were calculated for each age group.

For the ERD component, two MANOVAs, one for each condition, were conducted having the age groups as the factor and peak amplitude and peak latency as the dependent variables. Two other MANOVAs with the same structure were conducted for the ERS component.

The $\alpha$-level for all analyses was 0.05 . When MANOVA revealed significant main effects, follow up univariate tests (one- or two-way ANOVA) were employed. All analyses were performed using the software package SPSS (SPSS 15.0 for Windows).

\section{Results}

Mean values of the behavioral (RT) and electrophysiological N1 variables for both groups and both conditions are shown in Table 1. Behavioral results for the VR condition showed that RT was overall $47.48 \mathrm{~ms}$ larger in the older than in the young adults $[F(1,36)=27.037, P<0.0001]$.

\subsection{N1 component}

A clear N1 component was obtained from both groups and both conditions, as illustrated in Fig. 2. A comparison between groups indicated a significant difference between young and older adults [Wilks' Lambda $=0.683, F(2,35)=8.11, P=0.001$ ]. Univariate tests indicated that $\mathrm{N} 1$ peak latency was increased in older as compared to young adults $[F(1,36)=13.05, P=0.001]$. In addition, $\mathrm{N} 1$ amplitudes were smaller in older as compared to young adults $[F(1,36)=6.04, P=0.019]$.

\section{Table 1}

Mean and standard deviation (SD) values for electrophysiological variables (N1 amplitude and latency) and response time (RT) in the young (YA) and older adults (OA) groups.

\begin{tabular}{|c|c|c|c|c|c|}
\hline \multirow[t]{2}{*}{ Measure } & \multirow[t]{2}{*}{ Condition } & \multicolumn{2}{|l|}{ YA } & \multicolumn{2}{|l|}{$\mathrm{OA}$} \\
\hline & & Mean & SD & Mean & SD \\
\hline \multirow{2}{*}{ Amplitude $(\mu \mathrm{V})^{* \dagger}$} & NVR & -11.57 & \pm 6.89 & -7.85 & \pm 3.33 \\
\hline & VR & -13.58 & \pm 6.34 & -9.34 & \pm 3.86 \\
\hline \multirow[t]{2}{*}{ Latency $(\mathrm{ms})^{*}$} & NVR & 149.21 & \pm 19.67 & 192.89 & \pm 52.05 \\
\hline & VR & 152.37 & \pm 15.49 & 195.79 & \pm 51.19 \\
\hline $\mathrm{RT}(\mathrm{ms})^{*}$ & VR & 238.83 & \pm 23.64 & 286.31 & \pm 34.44 \\
\hline
\end{tabular}

Note: interaction between group and condition factors was not significant.

Variables with significant difference between age groups as indicated by univariate tests.

${ }^{\dagger}$ Variable with significant difference between conditions as indicated by univariate tests.
A comparison between conditions indicated a significant difference between NVR and VR conditions [Wilks' Lambda $=0.792$, $F(2,35)=4.59, P=0.017]$. Univariate tests indicated that $\mathrm{N} 1 \mathrm{ampli}-$ tude was larger in the VR condition than the NVR condition $[F(1,36)=8.39, P=0.006]$. No difference was obtained for $\mathrm{N} 1$ latency between conditions $[F(1,36)=0.804, \quad P=0.376]$. Additionally, no interaction was obtained between group and condition factors $[F(2,35)=0.095, P=0.910]$.

For the study of the correlation between behavioral and electrophysiological data, RT was plotted against both N1 amplitude and latency for the VR condition, separately for each age group (Fig. 3). Significant correlations were obtained only for the older group in which lower N1 peak amplitudes and higher N1 peak latencies were associated with larger response times.

\section{2. $E R D / E R S$}

ERD/ERS analysis showed a marked power decrease of beta rhythms (beta ERD), followed by beta power increase (beta ERS) in both age groups and conditions (Fig. 4). Note that in the left column the processing was focused on the ERD segment while in the right column the focus of the processing was on the ERS segment.

Mean values of ERD and ERS peak amplitude and latency for both groups and both conditions and their respective samples (participants with significant ERD/ERS indicated by CI analyses) are shown in Table 2. In the YA group, the mean baseline powers were $15.00( \pm 16.98) \mu \mathrm{V}^{2}$ and $11.60( \pm 12.38) \mu \mathrm{V}^{2}$ for the NVR and VR conditions, respectively. In the OA group, the mean baseline powers were $15.83( \pm 19.06) \mu V^{2}$ and $13.10( \pm 15.94) \mu V^{2}$ for the NVR and VR conditions, respectively.

For the NVR condition, MANOVA indicated no significant difference between young and older adults for the ERD component [Wilks' Lambda $=0.840, F(2,25)=2.39, P=0.112$ ]. For the ERS component, MANOVA indicated a significant difference between age groups [Wilks' Lambda $=0.543, \quad F(2,15)=6.30, \quad P=0.010$ ] Univariate tests indicated reduced ERS peak amplitude for the older compared to the young adults $[F(1,16)=11.73, P=0.003]$, but indicated no difference for the ERS peak latency between the age groups $[F(1,16)=2.80, P=0.113]$.

For the VR condition, MANOVA indicated a significant difference between young and older adults for the ERD component [Wilks' Lambda $=0.472, F(2,23)=12.85, P<0.001]$. Univariate tests indicated larger ERD peak amplitude for the OA $[F(1,24)=10.11$, $P=0.004]$ and delayed ERD peak latency for the older group $[F(1,24)=11.25, P=0.003]$. In addition, MANOVA indicated a significant difference between the age groups for the ERS component [Wilks' Lambda $=0.608, F(2,20)=6.45, P=0.007$ ]. Univariate tests indicated reduced ERS peak amplitude for the OA $[F(1,21)=5.51$, $P=0.029]$ and delayed ERS peak latency for the older group $[F(1,21)=6.73, P=0.017]$.

\section{Discussion}

Our results showed that brain electrophysiological measurements correlate with response time differences in the perception of passive ankle movement found between young and older adults. Comparisons between conditions VR and NVR provide important information for understanding the neural processing stages involved in ankle motion perception. These results are discussed below separately for N1 and ERD/ERS components.

\subsection{N1 component}

The prominent negative deflection (N1) after ankle movement onset observed in the present study, even in the absence of motor 

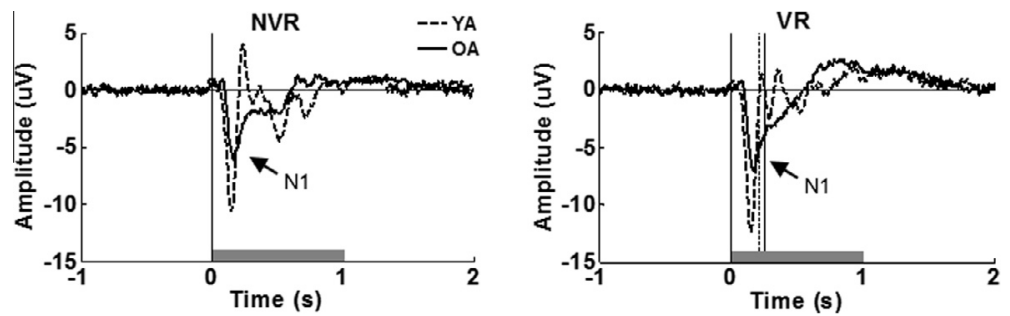

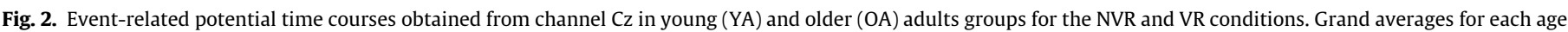

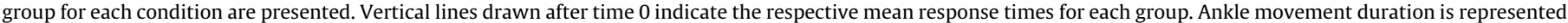
by a horizontal bar.

\section{YA}
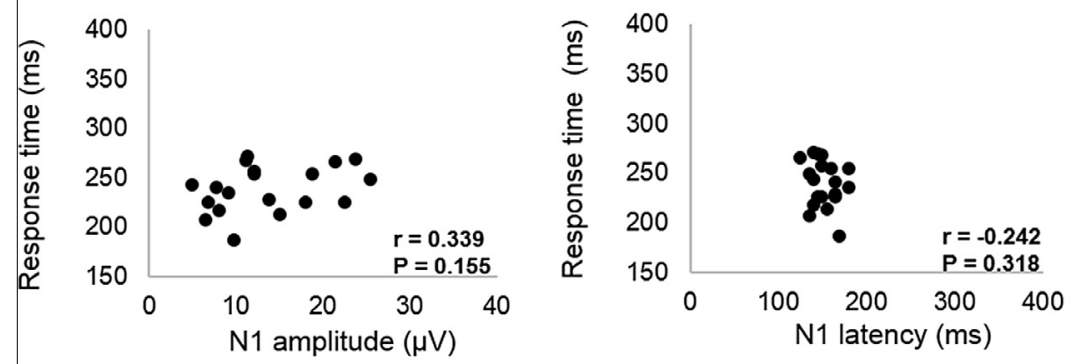

OA
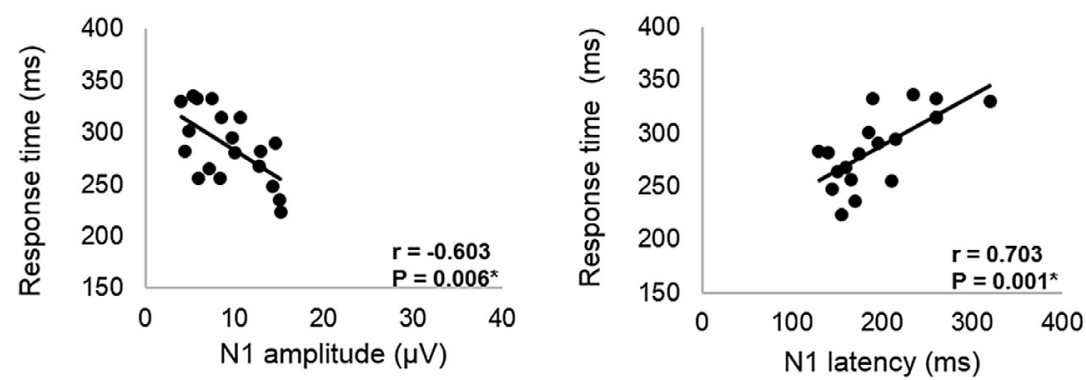

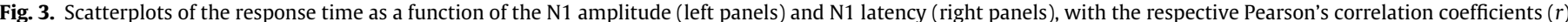

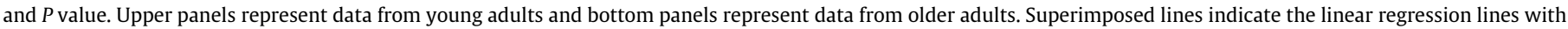
statistical significance $(P<0.05)$.
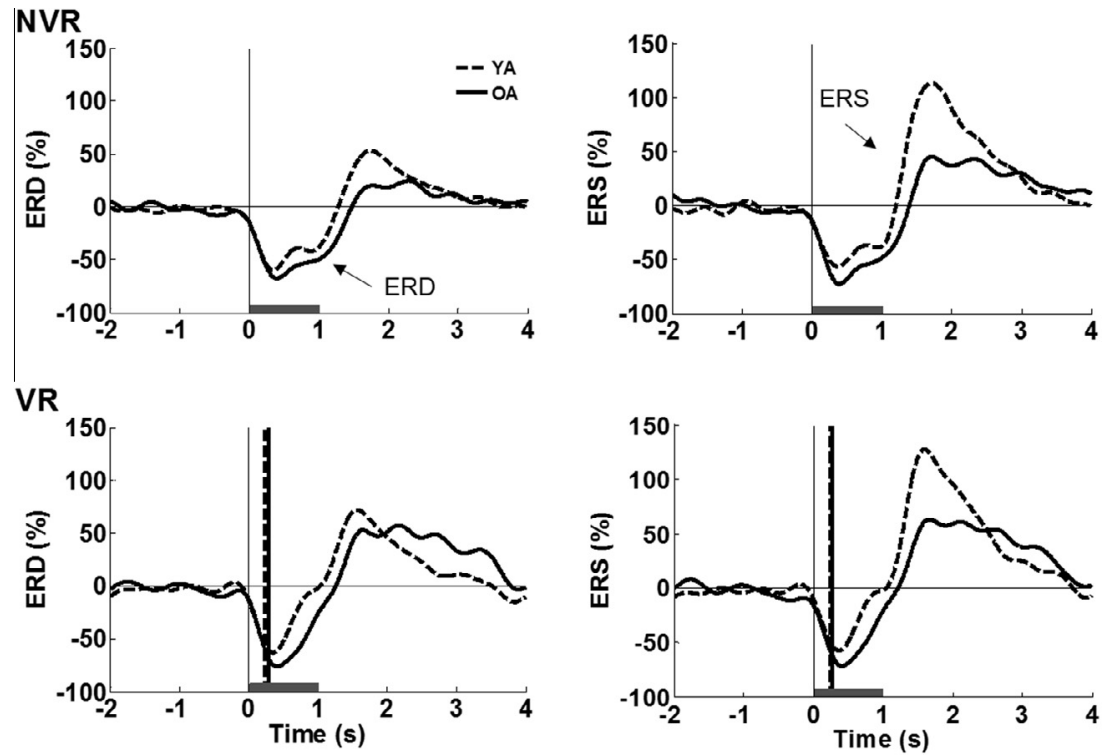

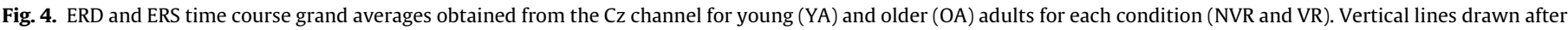
time 0 indicate the respective mean response times for each group. Ankle movement duration is represented as a horizontal bar. 
Table 2

Mean and standard deviation (SD) values for ERD and ERS variables in the young (YA) and older adults (OA) groups and the respective sample size ( $N$ ).

\begin{tabular}{|c|c|c|c|c|c|c|c|}
\hline \multirow[t]{2}{*}{ Measure } & \multirow[t]{2}{*}{ Conditions } & \multicolumn{3}{|l|}{ YA } & \multicolumn{3}{|l|}{$\mathrm{OA}$} \\
\hline & & Mean & SD & $N$ & Mean & SD & $N$ \\
\hline \multicolumn{8}{|l|}{$E R D$} \\
\hline \multirow{2}{*}{ Amplitude (\%) } & NVR & -60.69 & \pm 12.16 & 12 & -69.37 & \pm 13.30 & 16 \\
\hline & $\mathrm{VR}^{*}$ & -62.76 & \pm 8.23 & 12 & -76.77 & \pm 13.20 & 14 \\
\hline \multirow[t]{2}{*}{ Latency (ms) } & NVR & 336.25 & \pm 47.44 & 12 & 389.69 & \pm 78.58 & 16 \\
\hline & $\mathrm{VR}^{*}$ & 347.50 & \pm 41.59 & 12 & 430.36 & \pm 76.25 & 14 \\
\hline \multicolumn{8}{|l|}{ ERS } \\
\hline \multirow[t]{2}{*}{ Amplitude (\%) } & $\mathrm{NVR}^{*}$ & 130.00 & \pm 56.53 & 9 & 60.67 & \pm 22.16 & 9 \\
\hline & $\mathrm{VR}^{*}$ & 130.54 & \pm 74.14 & 12 & 84.32 & \pm 31.06 & 11 \\
\hline \multirow[t]{2}{*}{ Latency (ms) } & NVR & 1677.78 & \pm 123.70 & 9 & 1837.78 & \pm 258.58 & 9 \\
\hline & $\mathrm{VR}^{*}$ & 1578.33 & \pm 74.39 & 12 & 1828.18 & \pm 335.26 & 11 \\
\hline
\end{tabular}

Conditions with significant difference between age groups as indicate by univariate tests.

action (pressing a button), and the temporal similarities of the $\mathrm{N} 1$ potential across conditions support the view that this component reflects mainly a sensory processing. During passive joint movement, the somatosensory origin of early ERP was postulated from previous observations that $\mathrm{N} 1$ was absent in a patient with sensory loss related to a thalamic hemorrhage (Alary et al., 1998). More specifically, anesthetic procedures have indicated that such potentials are associated with the activation of muscle spindles, with little (if any) contribution from cutaneous and joint receptors (Abbruzzese et al., 1985; Starr et al., 1991; Mima et al., 1996). In addition, microneurographic techniques have shown that the essential proprioceptive sources of kinesthetic information of limb movement are the muscle spindles (Burgess et al., 1982; Burke et al., 1988), whereas cutaneous afferents have been shown to be partially active (Aimonetti et al., 2007) or even inactive (Ribot-Ciscar et al., 2013) during passive movement. In this sense, the $\mathrm{N} 1$ component observed in the present study must have been triggered by the discharges of muscle spindles from the triceps surae muscles.

The larger N1 amplitude in the VR condition, compared to NVR condition might reflect a higher cortical readiness when subjects are instructed to respond to the sensory stimulation, given that more attention must be allocated to the stimulus. Indeed, the modulation of early somatosensory ERP by attention has been shown for different types of mechanical stimulation (Eimer and Driver, 2000; Eimer et al., 2002; Hotting et al., 2003; Quant et al., 2004; Arnfred, 2005; Gherri and Eimer, 2008), with increased ERPs (e.g., N80, P100, N140) for attended compared to ignored stimulus condition.

The present results showed that early somatosensory potentials in older adults are delayed and attenuated, compared to young adults. Attenuated N1 amplitude in older adults is supposed to be related to their reduced selective attention, which was previously shown during response time paradigms (Falkenstein et al., 2001; Cabeza et al., 2002; Prakash et al., 2009; Vandenbossche et al., 2014). Furthermore, reduced amplitude of the sensory nerve action potential is related to reduction of axonal numbers with age (Rivner et al., 2001, Bouche et al., 1993) and this anatomical change is probably also reflected in the upper levels of the central nervous system. Apart from axonal loss, demyelination of the nerves is suggested to lead to reduced nerve conduction velocity (Verdu et al., 2000; Rivner et al., 2001). These changes, together with dysfunction in receptors, represented mainly by decrements in intrafusal fiber numbers (Liu et al., 2005) and reductions in nerve conduction velocity at the spinal cord level (Dorfman and Bosley, 1979), may contribute to the delayed N1 latency in older adults in the present study. However, the latency changes due to these non-encephalic structures of the nervous system are relatively small and cannot account for the cortical response latency changes found experimentally. At higher levels of the central nervous system, the loss of dopamine and dopaminergic receptors (Kaasinen et al., 2000; Volkow et al., 2000) and decreased white matter volume (Guttmann et al., 1998; Davis et al., 2009; Bennett and Madden, 2014) are documented to occur with aging and are likely contributing to increases in the central processing time.

Age-related slower sensory processing is also suggested to be related to delayed long-latency reflexes (LLR) during postural perturbations (Nardone et al., 1995; Allum et al., 2002). The reason for this assumption is that the LLR delay in older is, compared to young adults, more pronounced than the age-related delay in the short-latency reflex (SLR): $20 \mathrm{~ms}$ delayed for the former vs $5 \mathrm{~ms}$ delayed for the latter. Since soleus M-wave latency is not different between young and old adults, conduction velocity in afferent pathways seems to be more affected than in efferent motor nerves (Scaglioni et al., 2003). In addition, early cortical potentials evoked by perturbed upright stance are delayed in older adults by approximately $20 \mathrm{~ms}$ (Duckrow et al., 1999), supporting the hypothesis of increased afferent delay with aging. Interestingly, the early potential observed in the present study had a similar template to that obtained during postural perturbation (Duckrow et al., 1999; Quant et al., 2004) thus, they probably represent the same cortical processes.

The correlation analyses indicated that the increased RTs in older adults are mainly related to increased N1 latency and this relationship is reinforced when N1 and RT mean delays are compared: N1 occurred 43.42 ms later in older than in young adults, whereas the RT was $47.48 \mathrm{~ms}$ larger in the older group. These findings reveal that slower behavioral response to a somatosensory stimulus (as studied in the present protocol) in older adults is strictly related to the early stages of sensorimotor cortical processing. Different combinations of peripheral and central afferent factors, influenced by genetic and lifestyle differences, would be an important factor behind the variable $\mathrm{N} 1$ component in the older adults group. On the other hand, the absence of a significant correlation between RT and N1 in young adults indicates that the RT variability in young adults is due to a combination of sensory, cognitive, and motor factors.

Different results were previously shown with visual and auditory stimuli (Yordanova et al., 2004), in which the response times in older adults were correlated not to early, but to late cortical processing. In addition, RT to visual and auditory stimuli was only different between age groups in the choice-reaction task and not in the simple reaction task. Based on these findings, age-related slowing was assumed to be caused by a functional dysregulation of control systems, including auditory and visual cognitive processing rather than to modifications of neural substrate, e.g., anatomical changes. This is not the case of our results, which showed neurophysiological age-related differences for a simple reaction time 
task. Thus, different aging effects between the sensory systems can be postulated.

\section{2. $E R D / E R S$}

Clear beta band cortical changes were observed in both sensory and sensorimotor tasks (NVR and VR conditions, respectively). Age-related differences for ERD and ERS were shown to be dependent on the conditions assessed. For the NVR condition, only the ERS amplitude was different between the age groups, with attenuated amplitude observed for older adults. On the other hand, for the VR condition, all variables analyzed (ERD and ERS latencies and amplitudes) were different between the age groups. For this latter condition, older adults showed larger and delayed ERD and attenuated and delayed ERS peaks. This result implies that aging effects on cortical inhibition are present even in the absence of a motor/cognitive task, whereas the age-related differences in the cortical excitability (ERD) are not observed in the purely somatosensory task used in the present study. Previous findings support the notion of the existence of different neural networks for ERD and ERS during passive joint movement, by showing their individual topographic (Alegre et al., 2002) and spectral (Muller-Putz et al., 2007) characteristics. Accordingly, the specificity of the aging effects in the neural pathways is possibly represented by the different results observed between ERD and ERS in the present study.

Prominent beta ERS in both conditions could be associated with sensory afferent input related to the new limb position, as already suggested in previous studies with passive movement (Cassim et al., 2001; Alegre et al., 2002; Muller et al., 2003). In this sense, attenuated ERS in older adults might be related to a reduction of sensory afferent inflow during ankle movement. Attenuated ERS in older adults is already documented during muscle relaxation after maintained wrist contraction (Labyt et al., 2006) and is supposed to be related to changes at cortical inhibitory circuits with aging. For instance, studies with TMS techniques have shown less active inhibitory circuits, reduced short-interval intracortical inhibition, and reduced cortical reciprocal inhibition in older compared to young adults (Peinemann et al., 2001; Sale and Semmler, 2005; Oliviero et al., 2006; Fujiyama et al., 2012).

Regarding the ERD component, its peak occurred during the ankle dorsiflexion phase and, differently from the attenuated N1 component in older adults, the ERD amplitude in the NVR condition was larger in the older group. A possible reason for the larger ERD in the older group could be a higher cognitive effort to process a decreased afferent proprioceptive inflow (weaker and delayed N1) generated by passive movement. Studies have shown that cerebral aging is associated with a more complex and diffuse cortical activation during sensorimotor tasks. Larger activation of M1, prefrontal, premotor and supplementary motor areas are observed in older adults (Derambure et al., 1993; Sailer et al., 2000; Mattay et al., 2002; Ward and Frackowiak, 2003) and supposed to be an adaptive strategy to keep the performance of a motor task closer to the levels achieved by young adults (Derambure et al., 1993: Sailer et al., 2000; Ward and Frackowiak, 2003), as a way to compensate for structural and neurochemical changes (Onofrj et al., 2001; Mattay et al., 2002). This assumption could explain why ERD differences between age groups were observed only for the VR condition, demonstrating that adding a cognitive motor task to a proprioceptive assessment impairs the speed of sensorimotor information processing and increases the cognitive effort in older adults, in an attempt to properly perform the task.

\subsection{Study limitations}

Even though clear EEG changes were obtained in the current study, caution must be taken in order to avoid misinterpretation of the ERS results. For instance, the ERS peak occurred after the foot has returned to the initial position. This implies the possibility of overlapping responses between the two directions, i.e., such potential cannot be attributed exclusively to the dorsiflexion movement. In addition, when $\mathrm{CI}$ analyses were applied for ERS, 10 subjects of each group were excluded from the analyses for the NVR condition. For the VR condition, the number of excluded subjects was smaller ( 7 young and 8 older adults). Because of the exclusion of subjects from the analyses due to absence of significant changes (a procedure also used by others in this field, e.g., Neuper and Pfurtscheller, 2001; Muller et al., 2003; Muller-Putz et al., 2007), the interpretation of their statistical significance becomes somewhat limited. The reason for the absence of significant changes in these subjects could be attributed to the small signal-to-noise ratio, probably associated with the distance between the cortical representation area of the ankle and the recording electrodes. Another putative reason may be the possible overlapping responses between the two movement directions. Some methodological improvements should be implemented in further investigations, including: (i) larger number of EEG electrodes, in order to provide higher spatial resolution and analysis of responses from brain areas that could be also involved in the task (e.g., premotor and hand representation area); (ii) control of the subject's background conditions such as smoking status and alcohol and caffeine intake in order to guarantee similar background conditions between the subjects and; (iii) ERD/ERS analysis in other frequency ranges (e.g., mu) and in narrower bands, with estimation of the individual dominant frequency of the responses.

\subsection{Implications for clinical research}

Considering that the cortical potentials elicited by brisk ankle movement are similar to those obtained during postural disturbances which mimic a real-world situation associated with falls, the paradigm used in the present study could be used in experimental studies of the aging of the somatosensory system and its consequences to balance control. The present study showed evidence that the performance slowing in a somatosensory assessment is mainly related to sensory deficits caused by normal aging. Based on the present results, future investigations on how to improve the proprioceptive sensory inflow and, consequently, the response time, would be relevant. One question to be answered is if older adults can benefit from specific sensorimotor training (e.g., training focused on the proprioceptive system), improving their response time and presenting cortical correlates of such improvement.

Accordingly, the combination of electrophysiological techniques used in the present study with motor training tasks could give new insights into neuroplastic changes (Andrew et al., 2014). Another possibility would be to apply electrical or mechanical stimuli over the legs or feet as a way of furnishing improved proprioceptive information to the central nervous system (Collins et al., 2009; Magalhaes and Kohn, 2011, 2012; Ribot-Ciscar et al., 2013) and investigate the correlates between behavioral and neurophysiological changes.

\section{Conclusions}

From the combined results of ERP and ERD/ERS, we concluded that there are electrophysiological correlates at the cortical level of sensorimotor performance during assessment of ankle kinesthetic perception. The age-related delay in the response time to a predominantly proprioceptive stimulus generated by passive ankle motion is probably related to weaker and delayed proprioceptive afferent arrival at the cortex and also to slower cortical processes 
possibly associated with reduced selective attention. Furthermore, we suggest that the higher cortical activity (larger beta ERD) in older adults might represent a compensatory strategy, which leads to adequate performance in the sensorimotor task of the present study. Finally, the attenuated beta ERS in older adults may be related to changes in the intracortical inhibitory activity.

\section{Acknowledgements}

This research was funded by Grants from FAPESP (\#2011/17193-0) and CNPq (\#303313/2011-0).

DRT received a Ph.D. scholarship (Grant No. 2009/09286-9) and holds a Post-Doctoral Grant (Grant no. 2013/14667-7) from FAPESP.

Conflict of interest: The authors declare that there are no conflicts of interest.

\section{References}

Abbruzzese G, Berardelli A, Rothwell JC, Day BL, Marsden CD. Cerebral potentials and electromyographic responses evoked by stretch of wrist muscles in man. Exp Brain Res 1985;58:544-51.

Aimonetti JM, Hospod V, Roll JP, Ribot-Ciscar E. Cutaneous afferents provide a neuronal population vector that encodes the orientation of human ankle movements. J Physiol 2007;580:649-58.

Alary F, Doyon B, Loubinoux I, Carel C, Boulanouar K, Ranjeva JP, et al. Event-related potentials elicited by passive movements in humans: characterization, source analysis, and comparison to fMRI. NeuroImage 1998;8:377-90.

Alegre M, Labarga A, Gurtubay IG, Iriarte J, Malanda A, Artieda J. Beta electroencephalograph changes during passive movements: sensory afferences contribute to beta event-related desynchronization in humans. Neurosci Lett 2002;331:29-32.

Allum JH, Carpenter MG, Honegger F, Adkin AL, Bloem BR. Age-dependent variations in the directional sensitivity of balance corrections and compensatory arm movements in man. J Physiol 2002;542:643-63.

Amin DJ, Herrington LC. The relationship between ankle joint physiological characteristics and balance control during unilateral stance. Gait Posture 2014;39:718-22.

Andrew D, Haavik H, Dancey E, Yielder P, Murphy B. Somatosensory evoked potentials show plastic changes following a novel motor training task with the thumb. Clin Neurophysiol 2014;126:575-80.

Arnfred SM. Proprioceptive event related potentials: gating and task effects. Clin Neurophysiol 2005;116:849-60.

Bennett IJ, Madden DJ. Disconnected aging: cerebral white matter integrity and agerelated differences in cognition. Neuroscience 2014;276:187-205.

Bouche P, Cattelin F, Saint-Jean O, Leger JM, Queslati S, Guez D, et al. Clinical and electrophysiological study of the peripheral nervous system in the elderly. J Neurol 1993;240:263-8.

Burgess PR, Wei JY, Clark FJ, Simon J. Signaling of kinesthetic information by peripheral sensory receptors. Annu Rev Neurosci 1982;5:171-87.

Burke D, Gandevia SC, Macefield G. Responses to passive movement of receptors in joint, skin and muscle of the human hand. J Physiol 1988;402:347-61.

Cabeza R, Anderson ND, Locantore JK, McIntosh AR. Aging gracefully: compensatory brain activity in high-performing older adults. Neurolmage 2002;17:1394-402.

Cassim F, Monaca C, Szurhaj W, Bourriez JL, Defebvre L, Derambure P, et al. Does post-movement beta synchronization reflect an idling motor cortex? NeuroReport 2001;12:3859-63.

Chen R, Yaseen Z, Cohen LG, Hallett M. Time course of corticospinal excitability in reaction time and self-paced movements. Ann Neurol 1998;44:317-25.

Collins AT, Blackburn JT, Olcott CW, Dirschl DR, Weinhold PS. The effects of stochastic resonance electrical stimulation and neoprene sleeve on knee proprioception. J Orthop Surg Res 2009;4:3.

Davis SW, Dennis NA, Buchler NG, White LE, Madden DJ, Cabeza R. Assessing the effects of age on long white matter tracts using diffusion tensor tractography. NeuroImage 2009;46:530-41.

Derambure P, Defebvre L, Dujardin K, Bourriez JL, Jacquesson JM, Destee A, et al. Effect of aging on the spatio-temporal pattern of event-related desynchronization during a voluntary movement. Electroencephalogr Clin Neurophysiol 1993;89:197-203.

Deshpande N, Connelly DM, Culham EG, Costigan PA. Reliability and validity of ankle proprioceptive measures. Arch Phys Med Rehabil 2003;84:883-9.

Dorfman LJ, Bosley TM. Age-related changes in peripheral and central nerve conduction in man. Neurology 1979;29:38-44.

Duckrow RB, Abu-Hasaballah K, Whipple R, Wolfson L. Stance perturbation-evoked potentials in old people with poor gait and balance. Clin Neurophysiol 1999;110:2026-32.

Eimer M, Driver J. An event-related brain potential study of cross-modal links in spatial attention between vision and touch. Psychophysiology 2000;37: 697-705.
Eimer M, van Velzen J, Driver J. Cross-modal interactions between audition, touch, and vision in endogenous spatial attention: ERP evidence on preparatory states and sensory modulations. J Cogn Neurosci 2002;14:254-71.

Falkenstein M, Hoormann J, Hohnsbein J. Changes of error-related ERPs with age Exp Brain Res 2001;138:258-62.

Fitzpatrick R, McCloskey DI. Proprioceptive, visual and vestibular thresholds for the perception of sway during standing in humans. J Physiol 1994;478:173-86.

Fujiyama H, Hinder MR, Schmidt MW, Garry MI, Summers JJ. Age-related differences in corticospinal excitability and inhibition during coordination of upper and lower limbs. Neurobiol Aging 2012;33(1484):e1-e14.

Gherri E, Eimer M. Links between eye movement preparation and the attentional processing of tactile events: an event-related brain potential study. Clin Neurophysiol 2008;119:2587-97.

Goble DJ, Coxon JP, Wenderoth N, Van Impe A, Swinnen SP. Proprioceptive sensibility in the elderly: degeneration, functional consequences and plasticadaptive processes. Neurosci Biobehav Rev 2009;33:271-8.

Graimann B, Huggins JE, Levine SP, Pfurtscheller G. Visualization of significant ERD ERS patterns in multichannel EEG and ECoG data. Clin Neurophysio 2002:113:43-7.

Guttmann CR, Jolesz FA, Kikinis R, Killiany RJ, Moss MB, Sandor T, et al. White matter changes with normal aging. Neurology 1998;50:972-8.

Hjorth B. An on-line transformation of EEG scalp potentials into orthogonal source derivations. Electroencephalogr Clin Neurophysiol 1975;39:526-30.

Hotting K, Rosler F, Roder B. Crossmodal and intermodal attention modulate eventrelated brain potentials to tactile and auditory stimuli. Exp Brain Res 2003:148:26-37.

Jasper HH. Report of the committee on methods of clinical investigation of EEG Appendix: the ten twenty electrode system of the international federation. Electroencephalogr Clin Neurophysiol 1958;10:371-5.

Kaasinen V, Vilkman H, Hietala J, Nagren K, Helenius H, Olsson H, et al. Age-related dopamine D2/D3 receptor loss in extrastriatal regions of the human brain. Neurobiol Aging 2000;21:683-8.

Keinrath C, Wriessnegger S, Muller-Putz GR, Pfurtscheller G. Post-movement beta synchronization after kinesthetic illusion, active and passive movements. Int J Psychophysiol 2006;62:321-7.

Labyt E, Cassim F, Szurhaj W, Bourriez JL, Derambure P. Oscillatory cortical activity related to voluntary muscle relaxation: influence of normal aging. Clin Neurophysiol 2006;117:1922-30.

Lephart SM, Pincivero DM, Giraldo JL, Fu FH. The role of proprioception in the management and rehabilitation of athletic injuries. Am J Sports Med $1997 ; 25: 130-7$

Lewis GN, Byblow WD. Modulations in corticomotor excitability during passive upper-limb movement: is there a cortical influence? Brain Res $2002 \cdot 943 \cdot 263-75$.

Lewis GN, Byblow WD, Carson RG. Phasic modulation of corticomotor excitability during passive movement of the upper limb: effects of movement frequency and muscle specificity. Brain Res 2001;900:282-94.

Liu JX, Eriksson PO, Thornell LE, Pedrosa-Domellof F. Fiber content and myosin heavy chain composition of muscle spindles in aged human biceps brachii. J Histochem Cytochem 2005;53:445-54.

Lord SR, Ward JA. Age-associated differences in sensori-motor function and balance in community dwelling women. Age Ageing 1994;23:452-60.

Magalhaes FH, Kohn AF. Vibratory noise to the fingertip enhances balance improvement associated with light touch. Exp Brain Res 2011;209:139-51.

Magalhaes FH, Kohn AF. Imperceptible electrical noise attenuates isometric plantar flexion force fluctuations with correlated reductions in postural sway. Exp Brain Res 2012;217:175-86.

Mattay VS, Fera F, Tessitore A, Hariri AR, Das S, Callicott JH, et al. Neurophysiological correlates of age-related changes in human motor function. Neurology 2002;58:630-5

McChesney JW, Woollacott MH. The effect of age-related declines in proprioception and total knee replacement on postural control. J Gerontol A Biol Sci Med Sci 2000;55:M658-66.

Mima T, Terada K, Maekawa M, Nagamine T, Ikeda A, Shibasaki H. Somatosensory evoked potentials following proprioceptive stimulation of finger in man. Exp Brain Res 1996:111:233-45.

Muller-Putz GR, Zimmermann D, Graimann B, Nestinger K, Korisek G, Pfurtscheller G. Event-related beta EEG-changes during passive and attempted foot movements in paraplegic patients. Brain Res 2007;1137:84-91.

Muller GR, Neuper C, Rupp R, Keinrath C, Gerner HJ, Pfurtscheller G. Event-related beta EEG changes during wrist movements induced by functional electrical stimulation of forearm muscles in man. Neurosci Lett 2003;340:143-7.

Nardone A, Siliotto R, Grasso M, Schieppati M. Influence of aging on leg muscle reflex responses to stance perturbation. Arch Phys Med Rehabil 1995;76:158-65.

Neuper C, Pfurtscheller G. Evidence for distinct beta resonance frequencies in human EEG related to specific sensorimotor cortical areas. Clin Neurophysiol 2001;112:2084-97.

Niedermeyer E, Lopes da Silva FHLD. Electroencephalography - basic principles, clinical applications, and related fields. Maryland, Baltimore (USA): Lippincot Williams \& Wilkins: 1999.

Oliviero A, Profice P, Tonali PA, Pilato F, Saturno E, Dileone M, et al. Effects of aging on motor cortex excitability. Neurosci Res 2006;55:74-7.

Onofrj M, Thomas A, Iacono D, D'Andreamatteo G, Paci C. Age-related changes of evoked potentials. Neurophysiol Clin 2001;31:83-103.

Peinemann A, Lehner C, Conrad B, Siebner HR. Age-related decrease in paired-pulse intracortical inhibition in the human primary motor cortex. Neurosci Let 2001;313:33-6. 
Pfurtscheller G, Brunner C, Schlogl A. Lopes da Silva FH. Mu rhythm (de)synchronization and EEG single-trial classification of different motor imagery tasks. NeuroImage 2006;31:153-9.

Pickard CM, Sullivan PE, Allison GT, Singer KP. Is there a difference in hip joint position sense between young and older groups? J Gerontol A Biol Sci Med Sc 2003;58:631-5.

Prakash RS, Erickson KI, Colcombe SJ, Kim JS, Voss MW, Kramer AF. Age-related differences in the involvement of the prefrontal cortex in attentional control. Brain Cogn 2009;71:328-35.

Quant S, Adkin AL, Staines WR, Mcllroy WE. Cortical activation following a balance disturbance. Exp Brain Res 2004;155:393-400.

Reily EL. EEG recording and operation of the apparatus. In: Niedermayer E, Lopes da Silva F, editors. Electroencephalography. Baltimore: Lippincott Williams \& Wilkins; 1999. p. 122-42.

Ribot-Ciscar E, Hospod V, Aimonetti JM. Noise-enhanced kinaesthesia: psychophysical and microneurographic study. Exp Brain Res 2013;228:503-11.

Rivner MH, Swift TR, Malik K. Influence of age and height on nerve conduction. Muscle Nerve 2001;24:1134-41.

Sailer A, Dichgans J, Gerloff C. The influence of normal aging on the cortica processing of a simple motor task. Neurology 2000;55:979-85.

Sale MV, Semmler JG. Age-related differences in corticospinal control during functional isometric contractions in left and right hands. J Appl Physiol (1985 2005:99:1483-93.

Salles JI, Alves H, Costa F, Cunha-Cruz V, Cagy M, Piedade R, et al. Electrophysiological analysis of the perception of passive movement. Neurosci Lett 2011;501:61-6.

Scaglioni G, Narici MV, Maffiuletti NA, Pensini M, Martin A. Effect of ageing on the electrical and mechanical properties of human soleus motor units activated by the $\mathrm{H}$ reflex and M wave. J Physiol 2003;548:649-61.
Seiss E, Hesse CW, Drane S, Oostenveld R, Wing AM, Praamstra P. Proprioceptionrelated evoked potentials: origin and sensitivity to movement parameters. Neurolmage 2002;17:461-8.

Skinner HB, Barrack RL, Cook SD. Age-related decline in proprioception. Clin Orthop Relat Res 1984;184:208-11.

Starr A, Kristeva R, Cheyne D, Lindinger G, Deecke L. Localization of brain activity during auditory verbal short-term memory derived from magnetic recordings. Brain Res 1991;558:181-90.

Thelen DG, Brockmiller C, Ashton-Miller JA, Schultz AB, Alexander NB. Thresholds for sensing foot dorsi- and plantarflexion during upright stance: effects of age and velocity. J Gerontol A Biol Sci Med Sci 1998;53:M33-8.

Toledo DR, Barela JA. Age-related differences in postural control: effects of the complexity of visual manipulation and sensorimotor contribution to postural performance. Exp Brain Res 2014;232:493-502.

Tomberg C. Finger kinaesthesia: cognitive electrogeneses to attended joint input. NeuroReport 1999;10:2547-50.

Vandenbossche J, Coomans D, Homble K, Deroost N. The effect of cognitive aging on implicit sequence learning and dual tasking. Front Psychol 2014;5:154.

Verdu E, Ceballos D, Vilches JJ, Navarro X. Influence of aging on peripheral nerve function and regeneration. J Peripher Nerv Syst 2000;5:191-208.

Volkow ND, Logan J, Fowler JS, Wang GJ, Gur RC, Wong C, et al. Association between age-related decline in brain dopamine activity and impairment in frontal and cingulate metabolism. Am J Psychiatry 2000;157:75-80.

Ward NS, Frackowiak RS. Age-related changes in the neural correlates of motor performance. Brain 2003;126:873-88.

Yordanova J, Kolev V, Hohnsbein J, Falkenstein M. Sensorimotor slowing with ageing is mediated by a functional dysregulation of motor-generation processes: evidence from high-resolution event-related potentials. Brain 2004; 127:351-62. 